\title{
Modeling in Football Training: The Effect of Two Methods of Training Based on Small Sided Games and Repeated Sprints on Mood and Physical Performance among Footballers
}

\author{
Okba Selmi1 ${ }^{1,2}$, Wissam Ben Khalifa', Mehrzia Zouaoui' ${ }^{1}$, Hajer Sehli' ${ }^{1}$, Makrem Zghibi', \\ Anissa Bouassida ${ }^{1}$ \\ ${ }^{1}$ Research Unit “Sportive Performance and Physical Rehabilitation", High Institute of Sports and Physical Education, \\ University of Jendouba, Jendouba, Tunisia \\ ${ }^{2}$ Faculty of Sciences of Bizerte, University of Carthage, Bizerte, Tunisia \\ Email: makwiss@yahoo.fr
}

How to cite this paper: Selmi, O., Khalifa, W. B., Zouaoui, M., Sehli, H., Zghibi, M., \& Bouassida, A. (2017). Modeling in Football Training: The Effect of Two Methods of Training Based on Small Sided Games and Repeated Sprints on Mood and Physical Performance among Footballers. Advances in Physical Education, 7, 354-365. https://doi.org/10.4236/ape.2017.73029

Received: November 2, 2016

Accepted: August 25, 2017

Published: August 28, 2017

Copyright () 2017 by authors and Scientific Research Publishing Inc. This work is licensed under the Creative Commons Attribution International License (CC BY 4.0).

http://creativecommons.org/licenses/by/4.0/ (c) (i) Open Access

\begin{abstract}
The aim of the study was to compare the effect of additional practice/training of small-sided games (SSG) or repeated sprints (RS) on mood state, and physical performance in professional soccer players. Twenty four professional soccer players took part in this study (age: $17 \pm 0.19$ years). Participants were divided into two groups: small-sided gamed group (GSSG) performed 3 bouts of SSG ( 3 versus 3 players on $25 \times 30 \mathrm{~m}$ pitch size) and repeated sprint group (GRS) performed 3 bouts of RS $(6 \times 40+40$-m sprint with 20 s of passive recovery in-between). Both groups were trained over a period of seven weeks (2 sessions/weeks) with the usual practice. The profile of mood state (POMS), the YOYO intermittent recovery test (YOYOTRT), sprint 10-m and five-jump test were conducted before and after training program. After 7 weeks of training, no changes in mood were determined, but run distance improved in both groups. Sprint time and leg strength improved in the RSG only. Coaches and physical trainers could choose between these two training modalities according to the objective of their training, keeping in mind the brief and intense actions advantages of the RS shown in the present study.
\end{abstract}

\section{Keywords}

Small Sided Games, Repeated Sprint Ability, Mood, Players

\section{Introduction}

The realization of the football performance depends on several parameters, namely, the pace of the game, morphological, physical, physiological and psy- 
chological. One of the manifestations of these requirements is the predominant solicitation of aerobic metabolism during the match which reaches $90 \%$ of the total energy supplied (Helgerud et al., 2001; Hoff et al., 2002; Stolen et al., 2005). This value reflects a physical endurance quality developed to support the high pace for 90 minutes. Speed and power figure increasingly in football to achieve intermittent high intensity efforts.

To play high level football, it is becoming important to produce consistent physical and mental bases in young players with more specific training methods or programs in sports team activity, as the small sided games (SSG) (Dellal et al., 2012a) and the ability of repetitive sprints (RSA) (Bravo et al., 2008). When driving the current physical condition in football, two essential parameters must be considered: 1) the ball has to be as present as possible since it is the essential tool of the footballer; and 2) speed endurance which is the key to physical training in football consists of intensive actions. The main difference between SSG and RSA is the presence of the ball that would impose a specific activity by developing physical, technical and tactical aspects at once (Casamichana et al., 2010; Hill-Haas et al., 2010; Dellal et al., 2011; Dellal et al., 2012b; Aguiar et al., 2012; Castellano et al., 2013).

Several scientific studies have shown the importance of these two forms of training as methods that can improve physical performance and physiological responses of the players (Hill-Haas et al., 2009; Buchheit et al., 2009; Dellal et al., 2012b). Psychological states are influenced by the type of activity and the training load (Bresciani et al., 2011; Fry et al., 1993; Morgan et al., 1987). For this reason, sport psychology specialists have sought to develop reliable tests and surveys to determine the psychological state of players. The general principles suggest that the assessment of psychological states during a training period can be helpful to prevent and control adverse syndromes that are related to the workload such as anxiety, loss of concentration or bad mood (Kenttä et al., 2006). Regarding the psychological reactions, mood state is measured by the "Profile of Mood States" (POMS) (McNair, Droppleman, \& Lorr, 1992). This psychological inventory originally developed to measure mood state in psychology is frequently used to assess mood state in sports during training periods (Morgan et al., 1987; Hooper et al., 1997; Miranda et al., 2013). In this perspective, the tool has been widely used to explore the relationship between the training and the state of mood (McNair et al., 1992). Experimental studies with professional athletes have shown that physical activity can simultaneously increase and decrease the scores of POMS (O'Connor et al., 2005). The aim of the study was to compare the effect of additional practice/ training of small-sided games (SSG) or repeated sprints (RS) on mood state, and physical performance in professional soccer players.

\section{Methodology}

\subsection{Experimental Approach}

The effects of physical training with ball and intermittent work on the physical 
and psychological performance in soccer have not been studied. Therefore, this study aimed to compare the effects SSG and RSA training on the aerobic fitness and explosivity about a period of 7 weeks in soccer players. The experiment was established on the competitive mid-season period. Before and immediately after the 7-week training period (SSG vs. RSA), POMS, anthropometric measurements, The total meters run of YOYO intermittent recovery test (YOYOIRT) (Bangsbo et al., 2008), the $10 \mathrm{~m}$ sprint-performance and the five-jump test-relative (5JT-relative) were measured with all players. The players were randomly invited to train with SSG or RSA for 7 weeks. In addition to the SSG and RSA programs, all players have continued to participate in regular training sessions (technical and tactical) and official games. It was controlled that all players have received the same training load. Rating of perceived exertion (RPE; Borg CR-10 scale) (Foster et al., 2001) was also measured after each training session. All tests and training sessions were conducted on artificial grass soccer field at the same times of the day. Participants were asked to refrain from vigorous activity ( $48 \mathrm{~h}$ before), eating ( $3 \mathrm{~h}$ before) and drinking caffeine based beverages ( $8 \mathrm{~h}$ before) before the measures.

\subsection{Population}

A total of 24 male professional footballers playing in the same football club participated in this study (age: $18 \pm 0.1$ yrs; height: $1.77 \pm 0.06 \mathrm{~m}$, body mass: $69.3 \pm$ $10.1 \mathrm{~kg}$ ). Subjects experience of $6.2 \pm 0.31$ years and they train an average of 5 sessions per week. Participants were divided into two groups: 12 players have undergone the training of small games (GSSG) and 12 players have performed repeated sprints (GRS). Goalkeepers were excluded from the study as they did not participate in the same physical training program. They are all non-smokers, and do not consume any drugs or medicines during the study and they have not presented any compelling anomaly during the medical examination. All players signed written informed consent after being notified about the research procedures, benefits and risks. The study was conducted according to the Declaration of Helsinki and the protocol was fully approved by a local university research ethics committee and according to the ethical standards in sport and exercise science research.

\subsection{The Profile of Mood State}

Profile of Mood State (POMS) is a measurement tool is widely used in sport, and consists of 65 items to assess 6 states: tension, anger, confusion, depression, fatigue, vigor (McNair et al., 1992). Subjects were asked to respond in terms of "how you felt during the past week, including today" (McNair et al., 1992). This questionnaire is scored on a Likert five-point scale ( $0=$ not at all, $1=$ a little, $2=$ moderate, $3=$ a lot, $4=$ extreme). Two items include a reverse listing: "relaxed" for dimension "anxiety-tension" and "effective" to "confusion-bewilderment" dimension. The score of each subscale was calculated by adding the scores of different items. The score of the total disruption of the mood is calculated by add- 
ing the five negative mood states (tension, depression, anger, fatigue and confusion) and subtracting the positive mood state (vigor).

\subsection{Training Program}

Each modality of training was preceded by a standardized warm-up for a period of 20 minutes consisting of jogging, coordination movements and dynamic stretching and ended with $4 \times 10 \mathrm{~m}$ sprints

The GRS had to sprint a $40+40 \mathrm{~m}$ distance (Bravo et al., 2008). After a 20-sec passive rest, they started sprinting again: 3 bouts of 240 to $300-\mathrm{m}$ with passive recovery 20 -sec between repetitions and 3 minutes of active recovery between sets $\left(\left(3^{\star} 6(20+20 \mathrm{~m}) ; \mathrm{R}=20-\mathrm{sec}\right)\right)$. GSSG conducted a 3 vs. 3 SSG on a playing surface of $35 \mathrm{~m}$ long and $25 \mathrm{~m}$ wide. The duration of SSG intervention was 25 minutes accomplished as intervals consisting of 4 bouts of 4 minutes separated by 3 minutes of passive recovery in-between. The coaches constantly encouraged the players verbally to maintain a high work rate during the games and provide new balls when necessary to allow continuity of the play during the sessions. The objective of the players in the SSG training was to keep the possession of the ball for the longest time possible (Dellal et al., 2011).

\subsection{Yo-Yo Intermittent Recovery Test (YIRT)}

The YIRT is an incremental intensity test is used to evaluate aerobic performance (Bangsbo et al., 2008) and consists of repeated 20-m runs back and forth between the starting, turning, and finishing lines $\left(180^{\circ}\right.$ angle), and at a progressively increased speed, which is controlled by audio beeps from a tape recorder. The speed of the test was initially set at $5 \mathrm{~km} \cdot \mathrm{h}^{-1}$. The test was performed on a synthetic grass field in groups of 6 players, as suggested by Bangsbo et al. (2008). The test was stopped when a subject could no longer maintain the required running speed dictated by the beep for two consecutive occasions or felt that he could not complete the stage. The velocity of the last 1-min stage completed by each subjects was retained as the player's MAS. The total meter run was retained for the analysis.

\subsection{Sprint $10 \mathrm{~m}$}

This physical quality was evaluated on field by photocells (TEL.SI. srl, Vignola, Italie) for a distance of $10 \mathrm{~m}$ representing the startup speed, football players have performed three sprints of $10 \mathrm{~m}$, separated by a recovery period of $5 \mathrm{~min}$. the subject is invited to cover this distance in the shortest possible time.

\subsection{The Five-Jump Test (5JT)}

The 5JT test is a practical, validate and alternative to estimate lower limb explosive power of selected population (Chamari et al., 2005). The subject move through a series of 5 jumps strides. Feet must be together at the start and the end of the fifth jump. This test gives a good idea of the power of the lower limbs, especially the level of coordination. The absolute performance of 5 jump test is measured 
in meters ( $\mathrm{m}$ ) divided by 5 to find an average stride. The relative 5 Jump test is average stride divided by the length of the lower limbs (Chamari et al., 2008). The subjects performed two trials with the best were retained for the analysis. 5JT performance was expressed relatively to leg length (5JT-relative).

\subsection{Statistical Analysis}

Statistical analyses were performed using SPSS version 20 for Windows (SPSS Inc., Chicago, Il, USA). The normality of data sets was checked using the Kolmogorov-Smirnov test. Paired $t$-tests were used to compare POMS scores (i.e., tension, anger, confusion, depression, fatigue, vigor and TMD) and physical performance elicited by both training groups (i.e., 5JT-relative, YOYOIRT-distance and 10-m performance). Magnitude of change expressed as Cohen's d coefficient was employed to give a rigorous judgment about the differences between GSSG and GRS (Cohen, 1988). Effect sizes (ES) were considered trivial, small, medium and large respectively for values of 0 to $0.20,>0.20$ to $0.50,>0.50$ to 0.80 and $>0.80$ (Hopkins et al., 2009). As for the physical performance and the mood responses, a two-way analyses of variance (ANOVA) was used to examine the effect of the "Group" (GSSG or GRS), "Time" (pre- and post-training program) and their interaction (Group $\times$ Time) on the POMS scores, 5JT-relative, YOYOIRT-distance and 10-m performance). When a significant interaction effect was found, the analysis was completed with a post-hoc Bonferroni test. The level of statistical significance was set at $p<0.05$.

\section{Results}

Concerning the mood state variables, no significant main effects of condition and time and no significant interaction on the scores of tension, anger, confusion, depression, fatigue vigor and TMD were observed (Table 1). POMS scores were not significantly affected by neither "time" nor "group". Comparisons between pre and post-training program showed no significant differences in any of the POMS scores (all, $p>0.05$ ) (Table 2 and Table 3).

Concerning the physical variables, there was a significant main effect of Group on distance 10-m performance and 5JT-relative and a significant main effect of Time on YOYOIRT distance, 10-m performance and 5JT-relative (Table 4). Moreover, a significant interaction effect was found for these four latter variables (Table 4). Comparisons between pre and post-training program revealed that only for GSR and not GSSG, the 5JT-relative increased significantly $(p<0.05)$ and $10-\mathrm{m}$ performance decreased significantly $(p<0.05)$ whereas YOYOIRT distance increased significantly for both group training $(p<0.001)$ (Table 5 and Table 6).

\section{Discussion}

The aim of our study was to compare the effect of two training programs (GSSG and GRSA) on physical performance and mood among footballers. The results showed: 1) no significant variation in different POMS scores in both groups; and 
Table 1. Results of the ANOVA with $2 \times 2$ repeated measures [group ((repeated sprint $(\mathrm{GRS})$ and small-sided games (GSSG)) $\times$ Time (pre- and post-training period)].

\begin{tabular}{ccccccc}
\hline $\begin{array}{c}\text { Main Effects } \\
\text { Variables }\end{array}$ & \multicolumn{2}{c}{ Group } & \multicolumn{2}{c}{ Time } & \multicolumn{2}{c}{ Interaction } \\
\hline Anger & 0.64 & 0.04 & 1.08 & 0.08 & 0.24 & 0.02 \\
Confusion & 0.51 & 0.03 & 0.13 & 0.01 & 0.16 & 0.01 \\
Depression & 0.63 & 0.04 & 0.56 & 0.04 & 0.51 & 0.04 \\
Tension & 2.64 & 0.15 & 2.33 & 0.13 & 2.71 & 0.15 \\
Fatigue & 2.63 & 0.15 & 2.63 & 0.15 & 2.66 & 0.16 \\
Vigor & 3.80 & 0.20 & 2.66 & 0.16 & 3.51 & 0.16 \\
TMD & 3.84 & 0.20 & 3.85 & 0.20 & 4.01 & 0.21 \\
\hline
\end{tabular}

Note: TMD: total mood disturbance, ES: effect size.

Table 2. Comparison of POMS scores before and after the training period in small-sided games group $(\mathrm{n}=12)$.

\begin{tabular}{cccc}
\hline & T1 & T2 & ES \\
\cline { 2 - 3 } Variables & Mean \pm SD & Mean \pm SD & \\
\hline Tension & $4.76 \pm 2.44$ & $5.09 \pm 2.5$ & 0.14 \\
Anger & $5.80 \pm 2.11$ & $5.80 \pm 2.11$ & 0.01 \\
Confusion & $4.8 \pm 2.70$ & $4.90 \pm 2.41$ & 0.04 \\
Depression & $2.99 \pm 2.81$ & $3.11 \pm 2.31$ & 0.04 \\
Fatigue & $5.01 \pm 2.84$ & $4.81 \pm 2.33$ & 0.8 \\
Vigor & $19.98 \pm 3.44$ & $20.43 \pm 3.24$ & 0.01 \\
TMD & $103.39 \pm 7.15$ & $103.28 \pm 7.06$ & 0.01 \\
\hline
\end{tabular}

Note: T1: pre-training, T2: post-training, ES: effect size, TMD: total mood disturbance.

Table 3. Comparison of POMS scores before and after the training period in repeated sprint group $(\mathrm{n}=12)$.

\begin{tabular}{cccc}
\hline & T1 & T2 & ES \\
\cline { 2 - 3 } Variables & Mean \pm SD & Mean \pm SD & \\
Tension & $5.06 \pm 2.55$ & $4.8 \pm 2.43$ & 0.11 \\
Anger & $4.45 \pm 0.19$ & $4.75 \pm 2.19$ & 0.14 \\
Confusion & $4.2 \pm 2.33$ & $4.06 \pm 2.72$ & 0.06 \\
Depression & $3.02 \pm 2.46$ & $2.8 \pm 2.71$ & 0.09 \\
Fatigue & $3.75 \pm 2.7$ & $4.12 \pm 2.52$ & 0.15 \\
Vigor & $20.1 \pm 3.09$ & $20.03 \pm 3.6$ & 0.02 \\
TMD & $100.38 \pm 8.01$ & $100.5 \pm 7.98$ & 0.02 \\
\hline
\end{tabular}

Note: T1: pre-training, T2: post-training, ES: effect size, TMD: total mood disturbance.

2) aerobic performance has been improved in both groups while anaerobic capacity was only improved in the GRSA. 
Table 4. Results of the ANOVA with $2 \times 2$ repeated measures [group ((repeated sprint $(\mathrm{GRS})$ and small-sided games (GSSG)) $\times$ Time (pre- and post-training period)].

\begin{tabular}{ccccccc}
\hline \multirow{2}{*}{$\begin{array}{c}\text { Main Effects } \\
\text { Variables }\end{array}$} & \multicolumn{2}{c}{ Group } & \multicolumn{2}{c}{ Time } & \multicolumn{2}{c}{ Interaction } \\
\cline { 2 - 7 } & $\mathrm{F}(1,19)$ & ES & F $(1,19)$ & ES & F $(1,19)$ & ES \\
\hline YO-YOITR (m) & 3.79 & 0.19 & $19.77^{* * *}$ & $0.56^{* * *}$ & $8.99^{* * *}$ & $0.40^{* * *}$ \\
5JT-relative & $4.51^{*}$ & $0.24^{*}$ & $5.1^{*}$ & $0.29^{*}$ & $8.21^{* *}$ & $0.37^{* *}$ \\
Sprint 10-m (sec) & $4.85^{*}$ & $0.25^{*}$ & $6.11^{*}$ & $0.31^{*}$ & $9.33^{* *}$ & $0.39^{* *}$ \\
\hline
\end{tabular}

Note: YO-YOIRT: YO-YO intermittent recovery test, 5 JT-relative: five-jump test relative, ES: effect size, ${ }^{*} p$ $<.05,{ }^{* *} p<.01,{ }^{* * *} p<.001$.

Table 5. Comparison of physical tests before and after the training period in small-sided games group $(\mathrm{n}=12)$.

\begin{tabular}{cccc}
\hline \multirow{2}{*}{ Variables } & T1 & T2 & ES \\
\cline { 2 - 4 } & Mean \pm SD & Mean \pm SD & \\
\hline Sprint 10-m & $1.71 \pm 0.07$ & $1.71 \pm 0.08$ & 0.01 \\
FJT-relative & $2.24 \pm 0.18$ & $2.25 \pm 0.18$ & 0.06 \\
Distance YO-YOIRT $(\mathrm{m})$ & $1803.3 \pm 199.2$ & $2026 \pm 194.71^{* * *}$ & 1.17 \\
\hline
\end{tabular}

Note: T1: pre-training, T2: post-training, ES: effect size, YO-YOIRT: YO-YO intermittent recovery test, 5JT-relative: five-jump test relative, ES: effect size, ${ }^{* * *} p<0.001$.

Table 6. Comparison of physical tests before and after the training period in repeated sprint group $(\mathrm{n}=12)$.

\begin{tabular}{cccc}
\hline \multirow{2}{*}{ Variables } & T1 & T2 & ES \\
\cline { 2 - 4 } & Mean \pm SD & Mean \pm SD & \\
\hline Sprint $10-\mathrm{m}$ & $1.78 \pm 0.09$ & $1.75 \pm 0.11^{\star}$ & 0.31 \\
FJT-relative & $2.25 \pm 0.37$ & $2.37 \pm 0.12^{\star}$ & 0.45 \\
Distance YO-YOIRT $(\mathrm{m})$ & $1733.3 \pm 275$ & $1980 \pm 119.44^{* * *}$ & 1.2 \\
\hline
\end{tabular}

Note: T1: pre-training, T2: post-training, ES: effect size, YO-YOIRT: YO-YO intermittent recovery test, 5JT-relative: five-jump test relative, ES: effect size, ${ }^{*} p<0.05,{ }^{* *} p<0.01$, ${ }^{* * *} p<0.001$

The mood stability due to the absence of acute fatigue during the period of training which is explained by the good control of the workload and the balance between work and recovery (Kenttä et al., 2006). For example, Filaire et al., (2001) studied the psychological changes, physiological of footballers during a sports season. The results indicated that the mood scores were associated with the training load. This suggests that increasing the intensity, duration of training and the results of the games are linked to mood changes. Other research (Rietjens et al., 2005; Filaire et al., 2003; Silva et al., 2008), who studied the effect of an intense training program on biological modification and mood among professional footballers during the competitive period. They found physiological changes with increasing scores of POMS which explains the sharp increase in training load was associated with mood disturbances, decreased performance and biochemical changes. These studies suggest that mood responses and performance can be 
linked to specific overreaching parameters.

Aerobic fitness of the football player is of major importance. Indeed the results and statistical analyzes showed that seven weeks of SSG lead to increased distance of YOYOIRT. This improvement is due to cardio respiratory adaptations. Our results are similar to Bravo et al. (2008) which showed that interval running training program (training method of Helgerud et al., 2001) improved by $22 \%$ of the distance traveled and $5.7 \%$ maximum oxygen consumption. Impellizzeri et al. (2008) conducted a comparison between two running intervals training programs (Helgerud et al., 2001) and a program of small sided games on aerobic performance. These authors showed a significant improvement in aerobic power and the match performance as the total distance covered (from 9425 $\mathrm{m}$ to $9890 \mathrm{~m}$ ) and the intensity of the game (from $82.8 \%$ to $85.0 \%$ of maximum heart rate). This improvement in aerobic endurance is related to the specificity of the practice (time volume, improving the technical displacement), the pitch size and the number of players and encouragement of the coach (Rampinini et al., 2007). During small sided games predominant solicitation of aerobic metabolism which reached $70.8 \%$ even $90 \%$ of the total energy supplied (Hoff et al., 2002; Stolen et al., 2005; Hill-Haas et al., 2011; Halouani et al., 2014). This value reflects a developed physical endurance quality to support the high rate during the 90 minutes of play. The present study shows the lack of improvement in sprint performance $(10 \mathrm{~m})$ and relative 5 jump test. These results is agreement with the work of (Reilly \& White, 2005) which shows that improved explosive qualities were slightly marked following a training program based solely on integrated practice. Therefore small sided games practiced alone do not increase the explosive qualities.

A training program based on repeated sprints, improving aerobic fitness as one of the most important features in modern football (Hill-Haas et al., 2007; Bravo et al., 2008; Buchheit et al., 2010; Bishop et al., 2011). For example Bravo et al. (2008) studied the effect of a training program based on repeated sprint on aerobic fitness; they found an increase of $26.31 \%$ of the distance covered and $5.4 \%$ of VO2max. Some authors claim that a good VO2max is imperative in modern football (Hoff, 2005; Stolen et al., 2005). This parameter is significantly correlated with the distance covered per game (Haugen et al., 2014). The efficacy of repeated sprints is also reflected in the reduction of energy costs, which leads us to talk about the running economy that has a proportional relationship with the VO2max and the anaerobic threshold (Gist et al., 2014) and these parameters are important factor for endurance (Ramírez-Campillo et al., 2014; Macpherson et al., 2015). Improving aerobic performance is proportional to the total distance game with a doubling of number of sprints during competition (Chamari et al., 2005).

This study showed an improvement in $10 \mathrm{~m}$ performance. This result is confirmed by Tonnessen et al., (2011). Improving the performance of sprint is due to neuromuscular adaptations. These improvements is related to the repeat sprints, blockages and the change of direction that enhances the startup speed 
and reduce the contact time on the ground. Moreover, improving the sprint is accompanied by an increase in the index of five jump test which represents a determining factor in the explosivity. These results are not confirmed by Bravo et al., (2008), who showed that there were no changes in the explosivity variables. Finally, it is of importance to highlight some limitations of this study. The study sample was relatively small, thereby limiting the conclusions which could be made. It would be interesting to associate these responses with technical aspects such as game and match performance. Indeed, this study was conducted at the youth players. Therefore, it seems interesting to conduct further investigations with other categories to see the physical and psychological responses during training program for different levels and ages. Moreover, investigating these responses in the early season preparation phase is considerable to determine changes with fatigue and training load intensification. Such factors should be taken into consideration in future investigations.

\section{Conclusion}

This study showed that the mood state did not differ between pre-to-post SSG and RSA. In addition, RSA produces an improvement of different physical quality while SSG improved only aerobic performance. The use of SSG and RSA by physical trainers and coaches develops aerobic performance for exploration of mood stability.

\section{References}

Aguiar, M., Botelho, G., Lago, C., Maças, V., \& Sampaio, J. (2012). A Review on the Effects of Soccer Small-Sided Games. Journal of Human Kinetics, 33, 103-113. https://doi.org/10.2478/v10078-012-0049-x

Bangsbo, J., Iaia, F. M., \& Krustrup, P. (2008). The Yo-Yo Intermittent Recovery Test. Sports Medicine, 38, 37-51. https://doi.org/10.2165/00007256-200838010-00004

Bishop, D., Girard, O., \& Mendez-Villanueva, A. (2011). Repeated-Sprint Ability-Part II. Sports Medicine, 41, 741-756. https://doi.org/10.2165/11590560-000000000-00000

Bravo, D. F., Impellizzeri, F. M., Rampinini, E., Castagna, C., Bishop, D., \& Wisloff, U. (2008). Sprint vs. Interval Training in Football. International Journal of Sports Medicine, 29, 668-674. https://doi.org/10.1055/s-2007-989371

Bresciani, G., Cuevas, M. J., Molinero, O., Almar, M., Suay, F., Salvador, A., \& Gonzalez-Gallego, J. (2011). Signs of Overload after an Intensified Training. International Journal of Sports Medicine, 32, 338. https://doi.org/10.1055/s-0031-1271764

Buchheit, M., Laursen, P. B., Kuhnle, J., Ruch, D., Renaud, C., \& Ahmaidi, S. (2009). Game-Based Training in Young Elite Handball Players. International Journal of Sports Medicine, 30, 251. https://doi.org/10.1055/s-0028-1105943

Buchheit, M., Mendez-Villanueva, A., Delhomel, G., Brughelli, M., \& Ahmaidi, S. (2010). Improving Repeated Sprint Ability in Young Elite Soccer Players: Repeated Shuttle Sprints vs. Explosive Strength Training. The Journal of Strength \& Conditioning Research, 24, 2715-2722. https://doi.org/10.1519/JSC.0b013e3181bf0223

Casamichana, D., \& Castellano, J. (2010). Time-Motion, Heart Rate, Perceptual and Motor Behaviour Demands in Small-Sides Soccer Games: Effects of Pitch Size. Journal of Sports Sciences, 28, 1615-1623. https://doi.org/10.1080/02640414.2010.521168 
Castellano, J., Casamichana, D., \& Dellal, A. (2013). Influence of Game Format and Number of Players on Heart Rate Responses and Physical Demands in Small-Sided Soccer Games. The Journal of Strength \& Conditioning Research, 27, 1295-1303. https://doi.org/10.1519/JSC.0b013e318267a5d1

Chamari, K., Chaouachi, A., Hambli, M., Kaouech, F., Wisløff, U., \& Castagna, C. (2008). The Five-Jump Test for Distance as a Field Test to Assess Lower Limb Explosive Power in Soccer Players. The Journal of Strength \& Conditioning Research, 22, 944-950. https://doi.org/10.1519/JSC.0b013e31816a57c6

Chamari, K., Moussa-Chamari, I., Boussaidi, L., Hachana, Y., Kaouech, F., \& Wisløff, U. (2005). Appropriate Interpretation of Aerobic Capacity: Allometric Scaling in Adult and Young Soccer Players. British Journal of Sports Medicine, 39, 97-101.

https://doi.org/10.1136/bjsm.2003.010215

Cohen, J. (1988). The Effect Size. Statistical Power Analysis for the Behavioral Sciences. Abingdon: Routledge, 77-83.

Dellal, A., Hill-Haas, S., Lago-Penas, C., \& Chamari, K. (2011). Small-Sided Games in Soccer: Amateur vs. Professional Players' Physiological Responses, Physical, and Technical Activities. The Journal of Strength \& Conditioning Research, 25, 2371- 2381. https://doi.org/10.1519/JSC.0b013e3181fb4296

Dellal, A., Owen, A., Wong, D. P., Krustrup, P., van Exsel, M., \& Mallo, J. (2012b). Technical and Physical Demands of Small vs. Large Sided Games in Relation to Playing Position in Elite Soccer. Human movement science, 31, 957-969.

Dellal, A., Varliette, C., Owen, A., Chirico, E. N., \& Pialoux, V. (2012a). Small-Sided Games versus Interval Training in Amateur Soccer Players: Effects on the Aerobic Capacity and the Ability to Perform Intermittent Exercises with Changes of Direction. The Journal of Strength \& Conditioning Research, 26, 2712-2720. https://doi.org/10.1519/JSC.0b013e31824294c4

Filaire, E., Bernain, X., Sagnol, M., \& Lac, G. (2001). Preliminary Results on Mood State, Salivary Testosterone: Cortisol Ratio and Team Performance in a Professional Soccer Team. European Journal of Applied Physiology, 86, 179-184. https://doi.org/10.1007/s004210100512

Filaire, E., Lac, G., \& Pequignot, J. M. (2003). Biological, Hormonal, and Psychological Parameters in Professional Soccer Players throughout a Competitive Season. Perceptual and Motor Skills, 97, 1061-1072. https://doi.org/10.2466/pms.2003.97.3f.1061

Foster, C., Florhaug, J. A., Franklin, J., Gottschall, L., Hrovatin, L. A., Parker, S., Dodge, C. et al. (2001). A New Approach to Monitoring Exercise Training. The Journal of Strength \& Conditioning Research, 15, 109-115. https://doi.org/10.1519/00124278-200102000-00019

Fry, R. W., Lawrence, S. R., Morton, A. R., Schreiner, A. B., Polglaze, T. D., \& Keast, D. (1993). Monitoring Training Stress in Endurance Sports Using Biological Parameters. Clinical Journal of Sport Medicine, 3, 6-13. https://doi.org/10.1097/00042752-199301000-00003

Gist, N. H., Fedewa, M. V., Dishman, R. K., \& Cureton, K. J. (2014). Sprint Interval Training Effects on Aerobic Capacity: A Systematic Review and Meta-Analysis. Sports Medicine, 44, 269-279. https://doi.org/10.1007/s40279-013-0115-0

Halouani, J., Chtourou, H., Gabbett, T., Chaouachi, A., \& Chamari, K. (2014). Small-Sided Games in Team Sports Training: A Brief Review. The Journal of Strength \& Conditioning Research, 28, 3594-3618. https://doi.org/10.1519/JSC.0000000000000564

Haugen, T. A., Tønnessen, E., Hem, E., Leirstein, S., \& Seiler, S. (2014). VO2max Charac- 
teristics of Elite Female Soccer Players, 1989-2007. International Journal of Sports Physiology and Performance, 9, 515-521. https://doi.org/10.1123/ijspp.2012-0150

Helgerud, J., Engen, L. C., Wisloff, U., \& Hoff, J. (2001). Aerobic Endurance Training Improves Soccer Performance. Medicine and Science in Sports and Exercise, 33, 1925-1931. https://doi.org/10.1097/00005768-200111000-00019

Hill-Haas, S. V., Coutts, A. J., Dawson, B. T., \& Rowsell, G. J. (2010). Time-Motion Characteristics and Physiological Responses of Small-Sided Games in Elite Youth Players: The Influence of Player Number and Rule Changes. The Journal of Strength \& Conditioning Research, 24, 2149-2156. https://doi.org/10.1519/JSC.0b013e3181af5265

Hill-Haas, S. V., Coutts, A. J., Rowsell, G. J., \& Dawson, B. T. (2009). Generic versus Small-Sided Game Training in Soccer. International Journal of Sports Medicine, 30, 636-642. https://doi.org/10.1055/s-0029-1220730

Hill-Haas, S. V., Dawson, B., Impellizzeri, F. M., \& Coutts, A. J. (2011). Physiology of Small-Sided Games Training in Football. Sports Medicine, 41, 199-220. https://doi.org/10.2165/11539740-000000000-00000

Hill-Haas, S., Bishop, D., Dawson, B., Goodman, C., \& Edge, J. (2007). Effects of Rest Interval during High-Repetition Resistance Training on Strength, Aerobic Fitness, and Repeated-Sprint Ability. Journal of Sports Sciences, 25, 619-628.

https://doi.org/10.1080/02640410600874849

Hoff, J. (2005). Training and Testing Physical Capacities for Elite Soccer Players. Journal of Sports Sciences, 23, 573-582.

Hoff, J., Wisløff, U., Engen, L. C., Kemi, O. J., \& Helgerud, J. (2002). Soccer Specific Aerobic Endurance Training. British Journal of Sports Medicine, 36, 218-221. https://doi.org/10.1136/bjsm.36.3.218

Hooper, S. L., MacKinnon, L. T., \& Hanrahan, S. (1997). Mood States as an Indication of Staleness and Recovery. International Journal of Sport Psychology, 28, 1-12.

Hopkins, W., Marshall, S., Batterham, A., \& Hanin, J. (2009). Progressive Statistics for Studies in Sports Medicine and Exercise Science. Medicine Science in Sports Exercise, 41,3 .

Impellizzeri, F. M., Rampinini, E., Castagna, C., Bishop, D., Ferrari Bravo, D., Tibaudi, A., \& Wisloff, U. (2008). Validity of a Repeated-Sprint Test for Football. International Journal of Sports Medicine, 29, 899. https://doi.org/10.1055/s-2008-1038491

Kenttä, G., Hassmén, P., \& Raglin, J. S. (2006). Mood State Monitoring of Training and Recovery in Elite Kayakers. European Journal of Sport Science, 6, 245-253. https://doi.org/10.1080/17461390601012652

Macpherson, T. W., \& Weston, M. (2015). The Effect of Low-Volume Sprint Interval Training on the Development and Subsequent Maintenance of Aerobic Fitness in Soccer Players. International Journal of Sports Physiology \& Performance, 10, 332-338. https://doi.org/10.1123/ijspp.2014-0075

McNair, D. M., Droppleman, L. F., \& Lorr, M. (1992). Edits Manual for the Profile of Mood States: POMS.

Miranda, R. E. E. P. C., Antunes, H. K. M., Pauli, J. R., Puggina, E. F., \& Da Silva, A. S. R. (2013). Effects of 10-Week Soccer Training Program on Anthropometric, Psychological, Technical Skills and Specific Performance Parameters in Youth Soccer Players. Science \& Sports, 28, 81-87.

Morgan, W. P., Brown, D. R., Raglin, J. S., O’connor, P. J., \& Ellickson, K. A. (1987). Psychological Monitoring of Overtraining and Staleness. British journal of sports medicine, 21, 107-114. https://doi.org/10.1136/bjsm.21.3.107

O’Connor, P. J., \& Puetz, T. W. (2005). Chronic Physical Activity and Feelings of Energy 
and Fatigue. Medicine and Science in Sports and Exercise, 37, 299-305. https://doi.org/10.1249/01.MSS.0000152802.89770.CF

Ramírez-Campillo, R., Álvarez, C., Henríquez-Olguín, C., Baez, E. B., Martínez, C., Andrade, D. C., \& Izquierdo, M. (2014). Effects of Plyometric Training on Endurance and Explosive Strength Performance in Competitive Middle- and Long-Distance Runners. The Journal of Strength \& Conditioning Research, 28, 97-104. https://doi.org/10.1519/JSC.0b013e3182a1f44c

Rampinini, E., Impellizzeri, F. M., Castagna, C., Abt, G., Chamari, K., Sassi, A., \& Marcora, S. M. (2007). Factors Influencing Physiological Responses to Small-Sided Soccer Games. Journal of Sports Sciences, 25, 659-666. https://doi.org/10.1080/02640410600811858

Reilly, T., \& White, C. (2005). Small-Sided Games as an Alternative to Interval- Training for Soccer Players. Science and Football, 5, 355-358.

Rietjens, G. J., Kuipers, H., Adam, J. J., Saris, W. H. M., \& Breda, E. V. (2005). Physiological, Biochemical and Psychological Markers of Strenuous Training-Induced Fatigue. International Journal of Sports Medicine, 26, 16-26. https://doi.org/10.1055/s-2004-817914

Silva, A. S. R., Santhiago, V., Papoti, M., \& Gobatto, C. A. (2008). Psychological, Biochemical and Physiological Responses of Brazilian Soccer Players during a Training Program. Science \& Sports, 23, 66-72.

Stolen, T., Chamari, K., Castagna, C., \& Wisløff, U. (2005). Physiology of Soccer. Sports Medicine, 35, 501-536. https://doi.org/10.2165/00007256-200535060-00004

Tonnessen, E., Shalfawi, S. A., Haugen, T., \& Enoksen, E. (2011). The Effect of 40-M Repeated Sprint Training on Maximum Sprinting Speed, Repeated Sprint Speed Endurance, Vertical Jump, and Aerobic Capacity in Young Elite Male Soccer Players. The Journal of Strength \& Conditioning Research, 25, 2364-2370. https://doi.org/10.1519/JSC.0b013e3182023a65

\section{Submit or recommend next manuscript to SCIRP and we will provide best service for you:}

Accepting pre-submission inquiries through Email, Facebook, LinkedIn, Twitter, etc. A wide selection of journals (inclusive of 9 subjects, more than 200 journals)

Providing 24-hour high-quality service

User-friendly online submission system

Fair and swift peer-review system

Efficient typesetting and proofreading procedure

Display of the result of downloads and visits, as well as the number of cited articles

Maximum dissemination of your research work

Submit your manuscript at: http://papersubmission.scirp.org/

Or contact ape@scirp.org 